\title{
Total Antioxidant Status and Other Markers to Distinguish Severely Obese Volunteers with and without Metabolic Syndrome
}

\author{
Sharmistha Singh, Astha Dwivedi, Sandeep Kumar, Poonam Chandra Mittal ${ }^{*}$ \\ Department of Biochemistry, Faculty of Science, University of Allahabad, Allahabad, India \\ Email: *poonam_mittal@rediffmail.com
}

How to cite this paper: Singh, S., Dwivedi, A., Kumar, S. and Mittal, P.C. (2019) Total Antioxidant Status and Other Markers to Distinguish Severely Obese Volunteers with and without Metabolic Syndrome. Food and Nutrition Sciences, 10, 648-663. https://doi.org/10.4236/fns.2019.106048

Received: March 11, 2019

Accepted: June 23, 2019

Published: June 26, 2019

Copyright $\odot 2019$ by author(s) and Scientific Research Publishing Inc. This work is licensed under the Creative Commons Attribution International License (CC BY 4.0).

http://creativecommons.org/licenses/by/4.0/

\section{(c) (i) Open Access}

\begin{abstract}
Obesity $(\mathrm{Ob})$ is an accepted major risk factor for the metabolic syndrome (MetS), a combination of at least three of five risk factors, which predispose to high oxidative stress (OS), but all obese do not show symptoms of MetS. There is dearth of data comparing OS homeostasis of severely obese adults with and without MetS, and need for biomarkers to help in differential diagnosis. Erythrocytic lipid and protein damage markers, malondialdehyde (MDA) and protein carbonyl (PCO), antioxidant enzymes erythrocytic superoxide dismutase(SOD), catalase (CAT), plasma glutathione peroxidase (GPX), and total antioxidant capacity (TAC) as ferric-reducing-ability-of-plasma (FRAP) were compared to understand OS homeostasis among 102 severely Ob (body mass index > 30), $102 \mathrm{Ob}$ with severe (z-score > 2) MetS as per National Cholesterol Education Program-Adult Treatment Panel III guidelines and 100 healthy non-obese Controls. MDA/PCO and all antioxidant enzymes were lowest for ObMetS, followed by Ob, indicating greater damage to protein moieties of the erythrocytic membrane. Multiple regression analysis confirmed z-scores $>2$ as significant predictor of lowered enzymes and TAC. Receiver Operator Curve analysis predicted that TAC was the most potential biomarker for the diagnosis and prognosis of MetS with an Odds Ratio of 88.5 indicating the high probability that FRAP would be low for ObMetS (z-score $>2)$ than for $\mathrm{Ob}$ with $\mathrm{BMI}>30$, but $\mathrm{z}$-scores $<1$. TAC is qualified as the most effective biomarker to distinguish between severely obese respondents with and without metabolic syndrome, and as a useful candidate for study of homeostatic breakdown in metabolic syndrome and the importance of $\mathrm{z}$-score in assessment of MetS in obese respondents.
\end{abstract}

\section{Keywords}

Obesity, Body Mass Index, Metabolic Syndrome, Z-Score, Total Antioxidant Capacity, Biomarker 


\section{Introduction}

Obesity is defined as an excess of adiposity in the body, largely attributed to positive energy balance. It is a major public health concern due to its worldwide epidemic and the recognition of its link with several chronic diseases [1] clustered in the metabolic syndrome [2] [3], which is characterized by different combinations of three or more features of hyperglycemia, hypertriglyceridemia, low level of high-density lipoprotein cholesterol (HDL-C), hypertension and abdominal obesity, as defined by the criteria of the Third Report of the National Cholesterol Education Program Adult Treatment Panel III [4].

The underlying mechanisms of the pathophysiology of MetS are linked to inflammatory stress conditions leading to increased free radical formation [5], resulting in diabetes and cardiovascular complications. Systemic oxidative stress (OS) is significantly elevated in obese subjects, especially in those exhibiting a MetS phenotype, OS appears to be both, the cause and the consequence of obesity and associated disorders [2] because excess fat is the cause of inflammatory problems, and visceral fat has been reported to have the strongest correlation with MetS and OS [6].

Since obesity and other risk factors of MetS are mostly found together, there is little literature comparing obese respondents with and without MetS. In one such study which compared an obese group with MetS with an obese group without MetS, some differences in oxidative stress indices were observed, and the authors have underlined the need to explore this aspect further [5]. The etiology of obesity is multifactorial and includes genetic and environmental factors. All obese individuals may not show symptoms of MetS, and individuals having BMI > 30 but no symptoms of MetS have been categorized as metabolically healthy obese (MHO) individuals [7].

The present study was undertaken in view of the dearth of data comparing OS status of severely obese adults with and without MetS. OS is the result of imbalance between formation and elimination of reactive oxygen species (ROS), but its validation is difficult. Simultaneous evaluation of markers of ROS-induced modifications of lipids, DNA, and proteins, enzymatic players of redox status, and total antioxidant capacity of human body fluids is recommended [8] [9]. The mechanisms of damage for membranal lipid and protein moieties are different but linked. High PUFA containing erythrocytic membrane is peroxidized through free radical-induced chain reactions, raising the highly toxic, relatively stable aldehyde malondialdehyde (MDA), which can interact with DNA to influence gene expression and protein synthesis, and cause further damage by cross-linking proteins and covalently modifying membrane proteins [10] [11], an early marker of which is protein carbonylation, measured as PCO produced by the $\alpha$-amidation pathway or by oxidation of glutamyl side chains, or selected amino acids, or reaction of reducing sugars with lysine residues [12]. Some protein damage is reversible, while some appears irreversible. Carbonylation is a suitable index of OS because of its early formation and relative stability [13]. 
The cell has several mechanisms to ameliorate or restrict the damage due to ROS. Superoxide dismutase (SOD) converts superoxide radical $\left(\cdot \mathrm{O}_{2}\right)$ to hydrogen peroxide $\left(\mathrm{H}_{2} \mathrm{O}_{2}\right)$, which is rapidly converted by Fenton reaction into the very reactive $\cdot \mathrm{OH}$ radical, but catalase and glutathione peroxidase $(\mathrm{GPx})$ convert the $\mathrm{H}_{2} \mathrm{O}_{2}$ to $\mathrm{H}_{2} \mathrm{O}$, restoring homeostatic equilibrium. Most systems will work to restore homeostasis by increasing these antioxidants, but OS results when the adaptive response is insufficient. Therefore measurement of SOD, catalase and GPx activities constitute an effective way to assess circulating antioxidant defense in humans [14]. Further, the overall change in oxidative stress status is measured by the total antioxidant capacity (TAC) which is an indicator of the overall homeostatic efficacy.

In view of the above, the present study attempted to assess homeostatic balance in obese respondents with and without metabolic syndrome, by measuring erythrocytic lipid and protein damage, antioxidant enzymes and total antioxidant outcome, and explore them as potential biomarkers for risk assessment. Since MetS is a conglomerate of disorders, a derived parameter, the composite z-score, was used to categorize MetS respondents in terms of its severity.

\section{Material and Methods}

\subsection{Selection of Respondents}

In this case-control study, height and weight of a large cross-section of human volunteers, age 40 - 70 years, were measured following standard procedures, as recommended by WHO [15]. Body mass index (BMI) was computed as BMI = weight $(\mathrm{kg}) /[\text { height }(\mathrm{m})]^{2}$. Waist measurements were made around the abdomen at the level of the umbilicus.

Healthy respondents with normal BMI $\left(18-25 \mathrm{~kg} / \mathrm{m}^{2}\right)$ were assigned to the Control group. Those with BMI $>30$ were screened for their medical history to assess whether they suffered from MetS, as described by the US (NCEP) ATP III [4]. MetS respondents suffered from any three of the following risk factors, namely, Central obesity (waist circumference $\geq 102 \mathrm{~cm} / 40$ inches (male), $\geq 88$ $\mathrm{cm} / 35$ inches (female)), Dyslipidemia (TG $\geq 150 \mathrm{mg} / \mathrm{dl}, \mathrm{HDL}-\mathrm{C}<40 \mathrm{mg} / \mathrm{dL}$ (male), $<50 \mathrm{mg} / \mathrm{dL}$ (female)) and Blood pressure $\geq 130 / 85 \mathrm{mmHg}$ (or treated for hypertension) and Fasting plasma glucose $\geq 110 \mathrm{mg} / \mathrm{dl}$ ), and were designated ObMetS, while those with BMI $>30$ but no other risk factor were categorized as $\mathrm{Ob}$.

Z-score, defined as the number of standard deviation units from the sample mean, was computed for each risk factor of the NCEP-ATPIII criteria, and the composite z-score for each obese (BMI > 30) respondent was computed.

Composite $z$-score $=z$-score of waist circumference $+z$-score of Systolic Blood Pressure $+z$-score of Fasting Blood Glucose $+z$-score of HDL-cholesterol $+z$-score of Triglycerides.

Ob respondents had a $z$-score $<1$, while those with a $z$-score between 2 and 3 were categorized as suffering from severe MetSand were designated ObMetS. 
The significance of the study was explained to all respondents who fulfilled these inclusion and exclusion criteria, and those who gave their informed consent were enrolled. The study protocol was approved by the Institutional Ethics Committee of Population Resource \& Research Centre, Allahabad.

The final sample comprised of 100 Controls, $102 \mathrm{Ob}$ and $102 \mathrm{ObMetS}$. The groups were matched for gender and comprised of 55 males +45 females for Controls, 59 males +43 females for $\mathrm{Ob}$ and 62 males +40 females for ObMetS.

\subsection{Blood Collection, Processing and Storage}

Blood samples were collected, divided in anticoagulant and plain vials, and processed to obtain packed red blood cells (RBCs), plasma and serum. RBCs were further processed to obtain hemolysate by suspending $1.8 \mathrm{ml}$ of $\beta$-merceptoethanol-EDTA stabilizing solution $(0.05 \mathrm{ml}$ of $\beta$-merceptoethanol and $10 \mathrm{ml}$ of neutralized $10 \%$ EDTA as described by us [16], and stored at $-80^{\circ} \mathrm{C}$ until analysis.

\subsection{Assessment of Biochemical Measures}

\subsubsection{Fasting Blood Glucose and Lipid Profile}

The measurements of fasting blood glucose, total cholesterol, triglyceride and HDL cholesterol were performed with the autoanalyser kits manufactured by ERBA diagnostics Mannheim, Germany using semi autoanalyser Chem-7, Erba Manheim. The calculated LDL cholesterol was estimated using the Friedewald formula:

$$
\text { LDL-C }=\text { TC }- \text { HDL-C }-(\text { TG/5) }
$$

\subsubsection{Oxidative Damage Markers}

\section{1) Determination of Malondialdehyde (MDA)}

Malondialdehyde (MDA) was taken as the index for lipid peroxidation, and estimatedin hemolysate, by method of Niehaus \& Samuelsson [17]. $0.3 \mathrm{ml}$ of hemolysate was mixed with $0.1 \mathrm{M}$ phosphate buffer $(\mathrm{pH} 7.4)$, and $2 \mathrm{ml}$ of TBA-TCA-HClreagent containing 15\% (w/v) TCA, 0.375\% (w/v) TBA and 0.25 $\mathrm{N} \mathrm{HCl}$, incubated in boiling water bath for 30 minutes, incubated in boiling water bath for 30 minutes and centrifuged to obtain clear supernatant. Absorbance was measured at $534 \mathrm{~nm}$ using UV-Vis spectrophotometer (Thermo Scientific, USA). MDA was expressed as nmols of MDA per gram of hemoglobin.

\section{2) Determination of Protein Carbonyl (PCO)}

Plasma protein carbonyls ( $\mathrm{PCO}$ ) content was measured according to procedure of Levine et al. [18]. PCO group reacts with 2,4-dinitrophenylhydrazine (DNPH) to generate chromophoric dinitrophenylhydrazones. DNPH was dissolved in $\mathrm{HCl}$, after the $\mathrm{DNPH}$ reaction proteins were precipitated with an equal volume of $20 \%(\mathrm{w} / \mathrm{v})$ trichloroacetic acid and washed three times with $4 \mathrm{~mL}$ of an ethanol/ethyl acetate mixture (1:1). The resultant precipitates were dissolved in guanidine $\mathrm{HCl}(6 \mathrm{M})$ solution and the absorbance were measured at $370 \mathrm{~nm}$, using the molar extinction coefficient of DNPH, e $=22,000 \mathrm{M}^{-1} \cdot \mathrm{cm}^{-1}$ and the 
result was expressed in $\mathrm{nmol} / \mathrm{mg}$ protein.

\subsubsection{Enzymatic Antioxidants}

\section{1) Determination of $\mathrm{Cu} \mathrm{Zn}$ Superoxide Dismutase (SOD)}

The Superoxide dismutase (SOD) enzyme activity was estimated by the method of Marklund and Marklund [19] with slight modifications. $0.05 \mathrm{ml}$ of hemolysate was incubated with $0.05 \mathrm{M}$ Trissuccinate buffer $(\mathrm{pH} 8.5)$ at $37^{\circ} \mathrm{C}$ and reaction started by adding $0.1 \mathrm{ml}$ of $20 \mathrm{mMpyrogallol}$. The increase in absorbance was recorded at $420 \mathrm{~nm}$. The activity of SOD was expressed as units per milligram hemoglobin.

\section{2) Determination of Catalase Activity}

Catalase activity was estimated according to the method of Sinha et al. [20]. $0.1 \mathrm{ml}$ of haemolysate/plasma was incubated in $50 \mathrm{mM}$ phosphate buffer ( $\mathrm{pH}$ 7.4) containing $10 \mathrm{Mm} \mathrm{H}_{2} \mathrm{O}_{2}$ and dichromate acetic acid. Catalase activity can be measured by monitoring the decrease in absorbance of $\mathrm{H}_{2} \mathrm{O}_{2}$ at $240 \mathrm{~nm}$. Catalase is expressed as Unit/g $\mathrm{Hb}$ when estimated in hemolysate or unit/g protein when measured in plasma.

\section{3) Determination Glutathione Peroxidase Activity}

Plasma reduced GSH was measured based on the method prescribed by Rotruck et al. [21]. $20 \mu \mathrm{l}$ of plasma was added to reaction mixture containing $0.02 \%$ GSH, $10 \mathrm{mM} \mathrm{NaN}_{3}, 10 \mathrm{mM} \mathrm{H}_{2} \mathrm{O}_{2}$ and $400 \mu \mathrm{l}$ of $0.1 \mathrm{M}$ Tris-Cl buffer ( $\mathrm{pH}$ 7.4) and incubated at $37^{\circ} \mathrm{C}$. After incubation, $0.1 \mathrm{ml}$ of Ellman's reagent $(19.5 \mathrm{~g}$ 5,5'-dithiobisnitrobenzoic acid (DTNB) was added to reduce the -SH group to form a $412 \mathrm{~nm}$ chromophore. The activity was expressed as $\mu \mathrm{mol}$ of GSH consumed $/ \mathrm{min} / \mathrm{ml}$ of plasma and was calculated from a standard GSH plot.

\subsubsection{Determination of Total Antioxidant Capacity (TAC) by FRAP}

FRAP was estimated by the established protocol of Benzie and Strain [22]. $40 \mu \mathrm{l}$ plasma was added to $2 \mathrm{ml}$ of working FRAP solution containing acetate buffer, $\mathrm{pH}$ 3.6, $10 \mathrm{mM}$; 2,4,6-tripyridyl-s-triazine (TPTZ) in $40 \mathrm{mM} \mathrm{HCl}$ and $20 \mathrm{mM}$ $\mathrm{FeCl}_{3} \cdot 6 \mathrm{H}_{2} \mathrm{O}$, in the ratio of $10: 1: 1$, at $37^{\circ} \mathrm{C}$. $\mathrm{Fe}^{2+}$ - TPTZ complex thus formed was measured against working FRAP at $593 \mathrm{~nm}$. FRAP values were calculated and expressed as $\mu \mathrm{mol} \mathrm{Fe}(\mathrm{II}) / \mathrm{ml}$ of the plasma.

\subsubsection{Statistical Analysis}

Data were analyzed using Microsoft Excel 2010, Prism Graph Pad 5 and JASP 0.8 software. All results are presented as mean \pm standard deviation. The statistical significance of the differences was assessed using Student's t-test at 95\% confidence $(\mathrm{P}<0.05)$. Pearson correlations were obtained. Receiver operating characteristic (ROC) curve and area under ROC curve (AUC) of the MetS risk score were used to calculate Sensitivity and Specificity for each cut-off point. The cut-off point, which gave the maximum sum of sensitivity and specificity, was taken as the optimum value, and variables were categorized based on NCEP guidelines as described above. 


\section{Results}

The present study was conducted to compare biochemical measures in severely obese respondents with and without metabolic syndrome. Respondents were matched for age. $\mathrm{Ob}$ and ObMetS were matched for BMI while BMI of $\mathrm{C}$ was $22.8 \pm 1.51$ (Table 1$)$.

NCEP-ATP III prescribed diagnostic measures and consequent Composite MetS severity z-score, and other related clinical measures of respondents assigned to $\mathrm{C}, \mathrm{Ob}$ and ObMetS (Table 2) confirm the diagnostic differences between $\mathrm{Ob}$ and $\mathrm{ObMetS}$ and do not need elaboration. Statistically significant differences $(\mathrm{P}<0.05)$ were also seen between $\mathrm{C}$ and $\mathrm{Ob}$ with regard to waist circumference, fasting blood glucose, triglycerides, blood pressure, total cholesterol,

Table 1. General characteristics of respondents assigned to controls $(\mathrm{C})$, obese $(\mathrm{Ob})$ and obese with metabolic syndrome (ObMetS) groups.

\begin{tabular}{cccc}
\hline Demographic Data & C & Ob & ObMetS \\
\hline M/F & $55 / 45$ & $59 / 43$ & $62 / 40$ \\
Age $(\mathrm{yrs})$ & $57 \pm 10.23$ & $55.26 \pm 13.8$ & $59.04 \pm 8.85$ \\
Height $(\mathrm{cm})$ & $160.1 \pm 7.69$ & $159.6 \pm 6.47$ & $159.2 \pm 7.57$ \\
Weight $(\mathrm{kg})$ & $59.7 \pm 7.23$ & $82.8 \pm 6.43$ & $83.4 \pm 8.18$ \\
Body mass index $\left(\mathrm{kg} / \mathrm{m}^{2}\right)$ & $22.8 \pm 1.51$ & $32.5 \pm 1.30$ & $32.9 \pm 1.60$ \\
\hline
\end{tabular}

Table 2. NCEP:ATP III prescribed diagnostic measures and consequent composite MetS severity z-score, and other clinical biochemical measures of respondents assigned to controls $(\mathrm{C})$, obese $(\mathrm{Ob})$ and obese with metabolic syndrome (ObMetS).

\begin{tabular}{|c|c|c|c|c|}
\hline & & Controls & $\mathrm{Ob}$ & ObMetS \\
\hline Sample size $\mathrm{n}$ & & 100 & 102 & 102 \\
\hline \multicolumn{5}{|c|}{ NCEP: ATP III Diagnostic Criteria For Met S } \\
\hline Waist circumference & $\begin{array}{c}\text { Men: } \geq 101 \mathrm{~cm} \\
\text { Women: } \geq 88.9 \mathrm{~cm}\end{array}$ & $75.4 \pm 8.02$ & $101 \pm 11.9$ & $113.2 \pm 3.9$ \\
\hline Fasting Blood Glucose & $\geq 100 \mathrm{mg} / \mathrm{dl}$ & $86.9 \pm 9.1$ & $102.5 \pm 9.2$ & $167.3 \pm 3.91$ \\
\hline Triglyceride & $\geq 150 \mathrm{mg} / \mathrm{dl}$ & $130 \pm 18.8$ & $152.6 \pm 12.2$ & $239.4 \pm 35.4$ \\
\hline HDL-Cholesterol & $\begin{array}{c}\text { Men: } \leq 40 \mathrm{mg} / \mathrm{dl} \\
\text { Women: } \leq 50 \mathrm{mg} / \mathrm{dl}\end{array}$ & $54.2 \pm 7.1$ & $52.3 \pm 4.47$ & $34.2 \pm 3.55$ \\
\hline \multirow{2}{*}{ Blood Pressure } & Systolic $\geq 130 \mathrm{mmHg}$ & $115 \pm 5.22$ & $122.5 \pm 4.90$ & $148.9 \pm 12.04$ \\
\hline & Diastolic $>85 \mathrm{mmHg}$ & $75 \pm 7.2$ & $80.9 \pm 4.8$ & $95.3 \pm 9.51$ \\
\hline $\begin{array}{l}\text { Composite MetS } \\
\text { severity z-score }\end{array}$ & & $0.36 \pm 0.22$ & $0.54 \pm 0.31$ & $2.68 \pm 0.33$ \\
\hline \multicolumn{5}{|c|}{ Other related biochemical measures } \\
\hline Total Cholesterol & $150-250 \mathrm{mg} / \mathrm{dl}$ & $176 \pm 10.7$ & $200 \pm 14.07$ & $287.7 \pm 54.4$ \\
\hline Low density lipoprotein- $C$ & $\leq 150 \mathrm{mg} / \mathrm{dl}$ & $83.8 \pm 19.3$ & $158.4 \pm 13.33$ & $175.4 \pm 31.8$ \\
\hline $\begin{array}{l}\text { Very low density } \\
\text { Lipoprotein }\end{array}$ & $5-40 \mathrm{mg} / \mathrm{dl}$ & $30.01 \pm 10.01$ & $40.8 \pm 3.14$ & $45.02 \pm 10.6$ \\
\hline
\end{tabular}


LDL-cholesterol and VLDL cholesterol, but not HDL-C, even though the z-scores of the $\mathrm{Ob}$ was $<1$, and they did not fulfil any criteria for metabolic syndrome.

All OS indices, MDA, PCO, SOD, catalase, and plasma GPx and TAC as FRAP showed significant difference between $\mathrm{Ob}$ and ObMetS, which were both significantly different from Controls $(\mathrm{P}<0.0001)$. The ratio of MDA to PCO as well as SOD, catalase, GPx and TAC as FRAP was lowest in the ObMetS, followed by the $\mathrm{Ob}$ and was least in the Controls as presented in Table 3.

Since MDA and PCO increased in all groups, the per cent increase between pairs of groups was calculated, and are presented in Figure 1. It was maximum between Controls and ObMetS, followed by the difference between Controls and $\mathrm{Ob}$, but it was minimum between $\mathrm{Ob}$ and $\mathrm{ObMetS}$.

The percent differences for the groups under investigation for all other parameters, SOD, catalase, GPx and FRAP is presented in Figure 2. The pattern here differed from that for MDA and PCO. There was a consistent decline in all these parameters. Since these are all indices of antioxidant capacity, their decrease

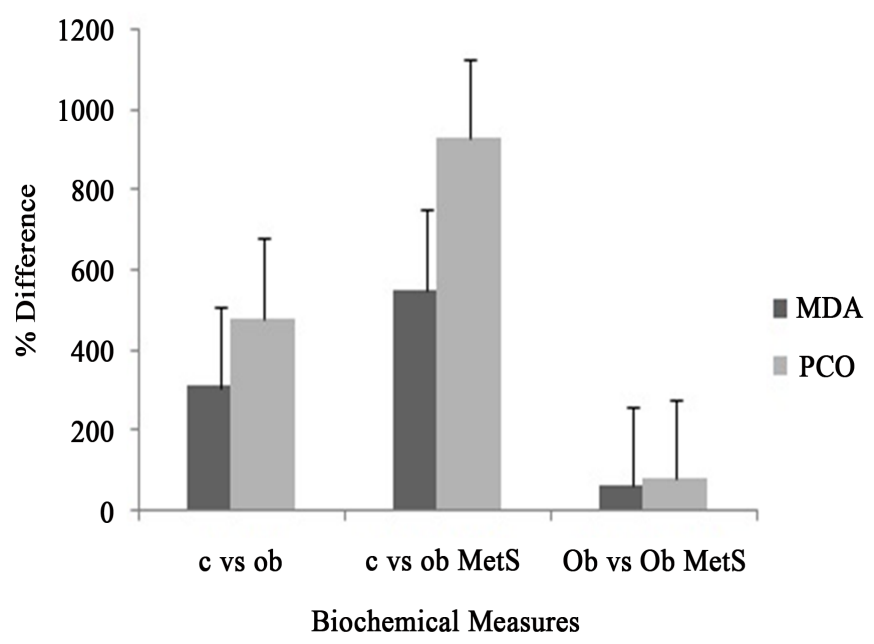

Figure 1. Relative per cent difference in MDA and PCO between various pairs of experimental groups.

Table 3. Erythrocytic and plasma oxidative stress markers of controls (C), obese (Ob) and obese with metabolic syndrome (ObMetS).

\begin{tabular}{cccc}
\hline Biochemical Markers & $\mathrm{C}$ & Ob & ObMetS \\
\hline Erythrocytic MDA (nmoles/g Hb) & $0.85 \pm 0.39$ & $3.47 \pm 1.07$ & $5.53 \pm 1.2$ \\
Erythrocytic PCO (nmole/g Hb) & $0.44 \pm 0.1$ & $2.55 \pm 0.78$ & $4.53 \pm 1.3$ \\
MDA/PCO & $2.01 \pm 1.01$ & $1.44 \pm 0.49$ & $1.31 \pm 0.3$ \\
Erythrocytic SOD (unit/g Hb) & $4.06 \pm 1.17$ & $2.84 \pm 1.09$ & $1.21 \pm 0.74$ \\
Erythrocytic CAT (unit/g Hb ) & $3.03 \pm 0.92$ & $2.29 \pm 0.65$ & $1.01 \pm 0.65$ \\
Plasma GPX (nmole/min/mg plasma protein) & $5.25 \pm 2.02$ & $4.3 \pm 1.8$ & $1.68 \pm 1.6$ \\
FRAP ( $\mu$ mole/ml of plasma) & $4.33 \pm 1.4$ & $2.97 \pm 0.9$ & $1.40 \pm 0.9$ \\
\hline
\end{tabular}

All values are expressed as Mean \pm SD. MDA: Malondialdehyde, PCO: Protein carbonyl, SOD: Superoxide dismutase, FRAP: Ferric reducing ability of plasma, GPX: Glutathione peroxidase, CAT: Catalase. 


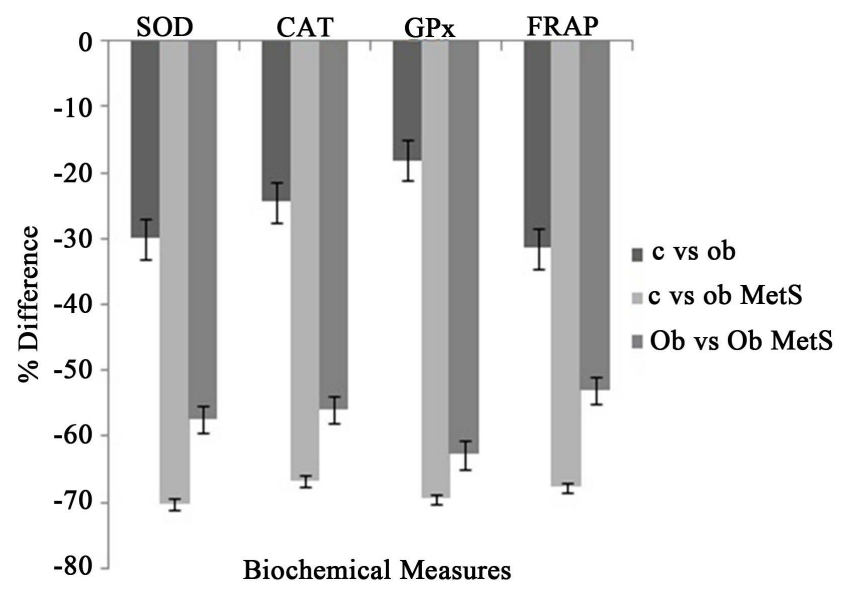

Figure 2. Relative per cent difference in SOD, CAT, GPx and FRAP between C and Ob, C and ObMetS, and between $\mathrm{Ob}$ and ObMetS.

from control values explained the increase in MDA and PCO. The difference was more between $\mathrm{Ob}$ and ObMetS groups than between $\mathrm{C}$ and $\mathrm{Ob}$, indicating that the $\mathrm{Ob}$ had adapted to the OS while the large difference between $\mathrm{Ob}$ and ObMetS indicated that the ObMetS failed to raise these adaptive antioxidant enzymes which ostensibly protected the $\mathrm{Ob}$ from major aberrations. The difference in per cent decline between Controls and ObMetS was maximum, as expected.

Further statistical tools were employed to explore whether this had some functional significance for comparing the biochemical impacts of these two conditions.

Since BMI $>30$ for $\mathrm{Ob}$ and $\mathrm{z}$-score $>2$ for the ObMetS were the independent variables used to group the respondents, correlation coefficients between BMI and $z$-score with indices of OS were obtained to assess interrelationships (Table 4).

MDA and PCO increased significantly with increasing BMI in the $\mathrm{Ob}$ and ObMetS, but not in Controls, but none of the other markers showed any relationship with BMI in any group. On the other hand, as z-score increased, MDA and PCO increased, accompanied by a significant negative relationship with SOD, catalase, GPx and FRAP (TAC). Since these are required for ameliorating OS and bringing the system back to equilibrium, a negative relationship indicated poor adaptation, which worsened as the z-scores increased.

Various OS indices responded differently to independent variables. Hence, BMI and z-score, primary data of selected biomarkers were reanalyzed using multiple regression, because regression analysis is widely used for prediction and forecasting, and to understand which among the independent variables are related to the dependent variable.

Multiple regression using stepwise method was performed for the $\mathrm{Ob}$ and ObMetS groups, with BMI and z-score as independent variables and OS indices as dependent variables.

It verified that higher MDA and PCO, and lower SOD (Table 5) were significant predictors of both, high BMI and high z-scores, but Catalase, GPx, and 
Table 4. Interrelationships between oxidative stress (OS) markers with body mass index (BMI) and z-scores, as indicated by Pearson's correlation coefficients $r$.

\begin{tabular}{cccccccc}
\hline Correlation coefficient between & & MDA & PCO & SOD & Catalase & GPx & FRAP \\
\hline \multirow{2}{*}{ BMI $\left(\mathrm{kg} / \mathrm{m}^{2}\right)$} & C & -0.131 & -0.17 & -0.234 & -0.119 & -0.065 & -0.135 \\
& Ob & $0.424^{*}$ & $0.344^{\star}$ & -0.269 & -0.155 & -0.067 & 0.005 \\
\multirow{2}{*}{ z-score } & ObMetS & $0.502^{\star}$ & $0.315^{*}$ & 0.11 & 0.004 & 0.071 & 0.046 \\
& ObMetS & $0.495^{\star}$ & $0.407^{*}$ & $-0.611^{*}$ & $-0.370^{*}$ & $-0.585^{*}$ & $-0.542^{*}$ \\
\hline
\end{tabular}

* indicates statistical significance at $\mathrm{P}<0.05$.

Table 5. Multiple regression using stepwise method for BMI $\left(\mathrm{kg} / \mathrm{m}^{2}\right)$ and $\mathrm{z}$-score as independent variable in $\mathrm{Ob}$ and ObMetS groups.

\begin{tabular}{|c|c|c|c|c|c|c|}
\hline \multirow[b]{2}{*}{ Variables } & \multicolumn{2}{|l|}{ BMI } & \multirow[b]{2}{*}{ Adjusted $\mathrm{r}^{2}$} & \multicolumn{2}{|l|}{ z-score } & \multirow[b]{2}{*}{ Adjusted $r^{2}$} \\
\hline & $\begin{array}{l}\text { Beta Coefficients } \\
\quad(95 \% \mathrm{CI})\end{array}$ & P Value & & $\begin{array}{l}\text { Beta Coefficients } \\
\quad(95 \% \mathrm{CI})\end{array}$ & P Value & \\
\hline $\begin{array}{l}\text { Erythrocytic } \\
\text { MDA }\end{array}$ & $\begin{array}{c}0.51 \\
(0.38 \text { to } 0.63)\end{array}$ & $<0.0001$ & & $\begin{array}{c}2.83 \\
(2.30 \text { to } 3.36)\end{array}$ & $<0.0001$ & \\
\hline $\begin{array}{c}\text { Erythrocytic } \\
\text { PCO }\end{array}$ & $\begin{array}{c}0.32 \\
(0.22 \text { to } 0.42)\end{array}$ & $<0.0001$ & & $\begin{array}{c}2.92 \\
(2.37 \text { to } 3.46)\end{array}$ & $<0.0001$ & \\
\hline $\begin{array}{l}\text { Erythrocytic } \\
\text { SOD }\end{array}$ & $\begin{array}{c}-0.22 \\
(-0.38 \text { to }-0.06)\end{array}$ & 0.006 & & $\begin{array}{c}-1.21 \\
(-1.58 \text { to }-0.83)\end{array}$ & $<0.0001$ & \\
\hline $\begin{array}{l}\text { Erythrocytic } \\
\text { catalase }\end{array}$ & $\begin{array}{c}-0.07 \\
(-0.17 \text { to } 0.02)\end{array}$ & 0.12 & 0.382 & $\begin{array}{c}-0.72 \\
(-1.09 \text { to }-0.36)\end{array}$ & $<0.0002$ & 0.531 \\
\hline Plasma GPx & $\begin{array}{c}-0.09 \\
(-0.37 \text { to } 0.18)\end{array}$ & 0.5 & & $\begin{array}{c}-2.59 \\
(-3.45 \text { to }-1.74)\end{array}$ & $<0.0001$ & \\
\hline FRAP (plasma) & $\begin{array}{c}0.003 \\
(-0.14 \text { to } 0.15)\end{array}$ & 0.96 & & $\begin{array}{c}-1.64 \\
(-2.10 \text { to }-1.18)\end{array}$ & $<0.0001$ & \\
\hline
\end{tabular}

TAC were significant predictors of OS in ObMetS, but did not show a significant rise with BMI alone. Thus, there appeared to be a significant difference in the OS response of $\mathrm{Ob}$ compared to ObMetS having similar BMI. The difference was more evident in the plasma indices.

OS indices were further assessed for their role as relative risk factors for distinguishing between patients of MetS as compared to healthy Ob. Area under receiver operator characteristic curve (AUC) of the MetS risk score were calculated for all OS indices (Figures 3(a)-(f)).

Sensitivity and specificity were calculated for each cut-off point, and the maximum sum of sensitivity and specificity was taken as the optimum value. Variables were categorized based on NCEP guidelines in the absence of classification criteria for OS markers as MetS components.

The AUC usually range from 0.5 (no discriminant capacity) to 1.0 (Perfect Discriminant Capacity). All OS markers studied here had high AUC (>0.86), hence they were very good markers, with good discrimination of predictive power, to distinguish between $\mathrm{Ob}$ and ObMetS. This is visible in the graphical representation of the AUC where the ROC graph is seen to be very close to the 


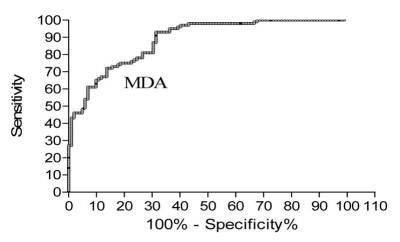

(a)

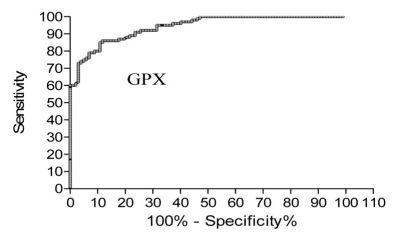

(d)

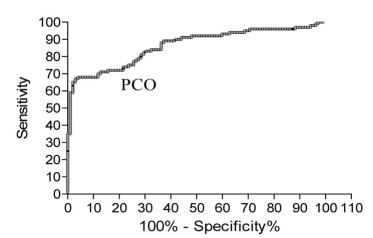

(b)

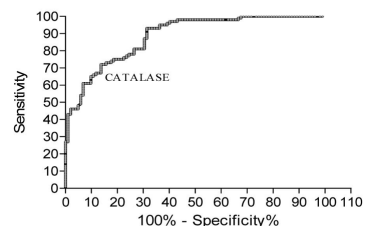

(e)

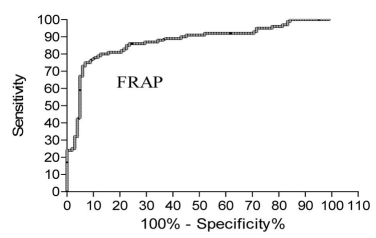

(c)

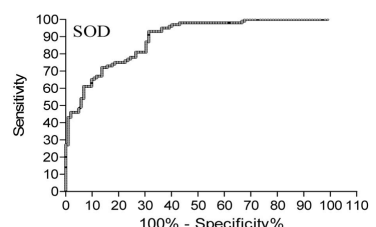

(f)

Figure 3. Area under receiver operator characteristic curve (AUC) of the MetS risk score for (a) MDA; (b) PCO; (c) FRAP; (d) GPx; (e) Catalase and (f) SOD for assessment as risk factors for metabolic syndrome as compared to non-diseased obese.

upper left corner, accompanied with high values of specificity and sensitivity, indicating their high clinical utility. A direct relationship was observed between the AUC as a diagnostic tool and the accuracy of the marker measured as specificity and sensitivity.

ROC curves were also used to obtain cut-offs to calculate the Odds Ratios (ORs), because they describe associations of biomarkers with clinical status (Table 6). TAC as FRAP emerged as the best clinical indicator, with an 88.5 times probability that FRAP would be lower than the cut-off of 1.1 in the ObMetS than in Ob. Other OS indicators also had good clinical importance, with ORs of 54.8 for lower catalase, 23.8 for higher MDA, 15 for lower SOD, 13 for lowered GPx and 8.8 for higher PCO in ObMetS as compared to Ob.

\section{Discussion}

The results obtained showed maximum systemic OS in ObMetS (z-scores $>2$ ), followed by $\mathrm{Ob}(\mathrm{BMI}>30)$ as indexed by all OS and antioxidant markers. The impact was greatest on MDA/PCO ratio and total antioxidant capacity, indicating more damage to the protein moiety of the erythrocytic membrane, and greater disturbance in the homeostatic processes in severe MetS, as distinct from severe obesity.

Free radical induced OS damaged both lipid and protein in the erythrocytic membrane, indicated by significantly higher levels of MDA and PCO in ObMetS (z-score $>2$ ), followed by Ob (BMI $>30$, z-score $<1)$. Increased MDA and PCO have been reported with obesity, hypercholesterolemia, diabetes, etc. [23] [24] [25] [26], which are all, individually, risk factors for MetS, yet there is dearth of data for the conglomerate called MetS [26]. There is also dearth of data on the relative damage to lipid and protein moieties of the erythrocytic membrane, both of which have structural and functional significance for the erythrocyte. The processes are linked, and damage to lipid enhances the damage to protein, as corroborated by the significant lowering of the MDA/PCO ratio which followed the sequence $\mathrm{ObMetS}<\mathrm{Ob}<\mathrm{C}$, supporting greater damage to protein 
Table 6. AUC of OS indices for predicting their use in distinguishing severe metabolic syndrome (ObMetS) and severe obesity $(\mathrm{Ob})$.

\begin{tabular}{ccccccccc}
\hline & GROUPS & AUC & SE & $\begin{array}{c}95 \% \text { CI } \\
\text { (AUC) }\end{array}$ & $\begin{array}{c}\text { P } \\
\text { Value }\end{array}$ & $\begin{array}{c}\text { Cut } \\
\text { off }\end{array}$ & $\begin{array}{c}\text { Odds ratio } \\
(\text { OR })\end{array}$ & $\begin{array}{c}95 \% \text { CI } \\
(\text { OR })\end{array}$ \\
\hline MDA & Ob vs. ObMetS & 0.896 & 0.022 & $0.852-0.94$ & $<0.0001$ & $>3.6$ & 23.8 & $68.7,62.2$ \\
PCO & Ob vs. ObMetS & 0.862 & 0.02 & $0.81-0.91$ & $<0.0001$ & $>2.1$ & 8.8 & $3.26,23.6$ \\
SOD & Ob vs. ObMetS & 0.88 & 0.022 & $0.841-0.928$ & $<0.0001$ & $<1.7$ & 15 & $7.52,29.9$ \\
Catalase & Ob vs. ObMetS & 0.9 & 0.02 & $0.86-0.92$ & $<0.0001$ & $<1.2$ & 54.8 & $19.8,151.5$ \\
GPx & Ob vs. ObMetS & 0.94 & 0.01 & $0.91-0.91$ & $<0.0001$ & $<3.4$ & 13.1 & $6.33,27.01$ \\
FRAP & Ob vs. ObMetS & 0.872 & 0.02 & $0.82-0.92$ & $<0.0001$ & $<1.1$ & 88.5 & $11.8,659.9$ \\
\hline
\end{tabular}

as OS becomes more severe. Paio et al. [26] have also reported that excessive OS forces an imbalance in protein turnover and favors protein damage and accumulation carbonylated proteins, recognized as a more stable marker of severe OS. Hopps and Caimi [27] have observed the paucity of data regarding protein oxidation in MetS although elevated levels of carbonyl groups have been frequently reported in individual risk factors of MetS. Although MDA and PCO are common measures of OS, the importance of their ratio has not been explored, and its significance in severe MetS needs further evaluation.

The importance of antioxidant enzymes, SOD, CAT and GPx in amelioration of OS has been discussed earlier, and the significance of their decrease is known. Hence it was not surprising that they were all lowest in the ObMetS followed by the $\mathrm{Ob}$. On a per cent basis, differences in all these enzymes were marginal between the Controls and the $\mathrm{Ob}$, but more severe between the $\mathrm{Ob}$ and the $\mathrm{Ob}$ MetS, underlining the limited role of obesity alone on OS as compared to the more severe impact of the other risk factors for MetS such as hyperglycemia, hypertension and dyslipidemia. The decline in these antioxidant enzymes may be a consequence of the increase in PCO due to irreversible damage to the membrane's protein structure and consequent inhibition of the enzymatic activity, increased susceptibility to proteolysis orimbalance in protein turnover resulting in damaged protein accumulation over degradation.

The present study is unique because it compares severely obese healthy respondents with those suffering from severe metabolic syndrome z-score $>2$. Such comparisons are lacking, even as a complex interplay between diabetes, obesity and OS has been suggested. Picu et al. [15] found newly diagnosed obese (BMI > 30) diabetics to have lower GPx and TAC, and a higher oxidant status which correlated positively with total body fat mass. In another study [16], Cu-Zn-SOD and Glutathione reductase became higher, and CAT, paraoxonase 1 and reduced glutathione declined as number of risk factors for MetS increased. Serrano et al. [17] also studied the impact of number of risk factors of MetS and found lower SOD and GPx in subjects with two MetS components compared with those having four or five MetS components. They suggested the predictive utility of the 
association between SOD and severity of MetS. Similarly, we suggest that the greater per cent difference of all antioxidant enzymes between $\mathrm{Ob}$ and ObMetS as compared to that between $\mathrm{Ob}$ and controls indicates that these could have a role in prediction of severity of MetS.

The overall OS status of any system depends on the balance between the large number of antioxidant processes which include many enzymes and an even larger number of non-enzymatic antioxidants such as vitamins and other free radical scavengers and the prooxidant free radicals. It is neither possible to estimate all of them nor is it easy to assess so much data, hence it is important to assess TAC. Of several methods used for this, FRAP is a simple, convenient, speedy method that gives reproducible results, and there is no apparent interaction between antioxidants. It is a commonly used index of non-enzymatic total antioxidant capacity in plasma, and its decline indicates poor redox balance.

In the present study, as expected, TAC was lowest in the ObMetS followed by the $\mathrm{Ob}$, and was highest in the healthy controls. This is supported by several reports on various risk factors of MetS, but none of them have organized the MetS on the basis of severity as assessed by z-score. Ravi Kiran et al. [28] found a lower TAC in diabetic and MetS respondents, Picu et al. [29], found low TAS along with low antioxidant enzymes, suggesting a strong association between T2DM and obesity, insulin resistance and OS, Bakhtiyari et al. [30] reported a far greater effect of MetS than age on OS in senior women, as indicated by a strong correlation of high TG and low HDL-C, with MDA and TAC. Hopps et al. [31] found significantly lower TAS in MetS non-diabetics but not in diabetic MetS respondents, and like us, they concluded that the evaluation of TAS may be a useful marker in the monitoring of MetS.

However, TAC may not increase in all conditions of OS. Costa et al. [32] did not find any association of TAC with higher levels of body weight, waist circumference, diastolic blood pressure, total cholesterol HDL-C ratio, and lower HDL-C in non-obese clinically healthy young adults, and concluded that this may be due to compensatory mechanisms that get activated in physiological conditions. This viewpoint is supported by other studies [31] where MDA increased but TAC was not affected. This has been attributed to an increase in antioxidant enzymes such as SOD, supporting the hypothesis that homeostatic mechanisms involving the antioxidant enzymes are able to produce sufficient adaptation to keep the total antioxidant levels unaffected in some conditions but not in others. This suggests the importance of TAC as a diagnostic tool for disease diagnosis.

From the foregoing, it is indicated that while there is considerable literature on the impact of individual risk factors of MetS on OS but there is dearth of efforts exploring relationships of OS indices with overall severity of MetS. Since MetS is a conglomerate of a broad spectrum of risk factors, symptoms and a range of biochemical aberrations, it is useful to categorize its severity using the composite index of z-scores. Obesity is considered as the most important risk factor, hence BMI is also an important independent variable.

Therefore, relationships between independent variables, BMI $>30$ and z-score $>$ 
2 on all the dependent OS indices were assessed. Results indicated that z-score was a better indicator of OS in MetS respondents than BMI. Multiple regression analysis of the data confirmed the trend obtained from the correlation matrix that BMI is a significant predictor of high MDA, PCO and low SOD but not of low CAT and GPx and high FRAP, while z-scores $>2$ are significant predictors of lowered SOD, CAT, GPx as well as FRAP, highlighting the importance of $z$-score in assessment of MetS in obese respondents.

These correlates of OS were further assessed as individual risk factors to distinguish $\mathrm{Ob}$ with $\mathrm{BMI}>30$ from ObMetS $\mathrm{z}$-score $>2$, by obtaining receiver operator characteristic curve (AUC) to calculate optimum value cut-off points for maximum sum of sensitivity and specificity which were used to compute Odds Ratios. Although all OS markers studied here were found to have high clinical utility, FRAP emerged as the best diagnostic risk factor for assessing severity of MetS. There was an 88.5 times probability that FRAP would be lower for respondents having z-score $>2$ than for respondents who were severely obese BMI $>30$, but had $\mathrm{z}$-scores $<1$ and did not suffer from the risk factors for MetS. The odds of having a lower erythrocytic catalase were 54.8 times, a higher MDA 23.8 times, a lower erythrocytic SOD 15 times, plasma GPx 13 times and higher PCO 8.8 times. Thus, FRAP is the best candidate to qualify as a diagnostic tool to distinguish between severely obese respondents with and without metabolic syndrome, followed by erythrocytic catalase, SOD, GPx and PCO in that order, which are also candidates of diagnostic significance.

\section{Conclusion}

From the above, we can conclude that the redox balance is significantly more severely disturbed in the group suffering from severe metabolic syndrome as compared to the severely obese. The strikingly high increase in total antioxidant capacity makes it a useful candidate for study of homeostatic balance in metabolic syndrome. Metabolic syndrome may be seen as a breakdown of the homeostatic processes which depend on a large number of enzymes such as SOD, catalase, GPx etc. and also on non-enzymatic antioxidants. Thus, total antioxidant capacity (TAC) is proposed as an important diagnostic tool for prognosis in obese respondents for metabolic syndrome. More in-depth studies are suggested in this direction.

\section{Acknowledgements}

Financial assistance by Council for Scientific and Industrial Research (CSIR) in form of JRF and Department of Science and Technology (DST) in form of UGC CRET for financial support is acknowledged. DST-FIST grant to the Biochemistry Department, University of Allahabad is also acknowledged.

\section{Conflicts of Interest}

The authors declare no conflicts of interest regarding the publication of this paper. 


\section{References}

[1] WHO Technical Report Series 916 (2003) Diet, Nutrition and the Prevention of Chronic Diseases. Report of a Joint WHO/FAO Expert Consultation, Geneva.

[2] Carrier, A. (2017) Metabolic Syndrome and Oxidative Stress: A Complex Relationship. Antioxidants \& Redox Signaling, 26, 429-431.

https://doi.org/10.1089/ars.2016.6929

[3] Hurrle, S. and Hsu, H.W. (2017) The Etiology of Oxidative Stress in Insulin Resistance. Biomedical Journal, 40, 257-262. https://doi.org/10.1016/j.bj.2017.06.007

[4] National Cholesterol Education Program (NCEP) (2002) Expert Panel on Detection E, and Treatment of High Blood Cholesterol in Adults (Adult Treatment Panel III). Third Report of the National Cholesterol Education Program (NCEP) Expert Panel on Detection, Evaluation, and Treatment of High Blood Cholesterol in Adults (Adult Treatment Panel III) Final Report. Circulation, 106, 3143-3421. https://doi.org/10.1161/circ.106.25.3143

[5] Skalicky, J., Muzakova, V., Kandar, R., Milan Meloun, M., Rousar, T. and Palicka, V. (2008) Evaluation of Oxidative Stress and Inflammation in Obese Adults with Metabolic Syndrome. Clinical Chemistry and Laboratory Medicine, 46, 499-505. https://doi.org/10.1515/CCLM.2008.096

[6] Heredia, F., Martinez Gomez, S. and Marcos, A. (2012) Obesity, Inflammation, and the Immune System. Proceedings of the Nutrition Society, 71, 332e8.

https://doi.org/10.1017/S0029665112000092

[7] Karelis, A.D., Faraj, B., Bastard, J.P., St-Pierre, D.H., Brochu, M., Prud'homme, D., et al. (2005) The Metabolically Healthy But Obese Individual Presents a Favorable Inflammation Profile. The Journal of Clinical Endocrinology \& Metabolism, 90, 4145-4150. https://doi.org/10.1210/jc.2005-0482

[8] Venturini, D., Simão, A.N.C., Scripes, N.A., Bahls, L.D., Melo, P.A.S., Belinetti, F.M., Lozovoy, M.A.B. and Dichi, I. (2012) Evaluation of Oxidative Stress in Overweight Subjects with or without Metabolic Syndrome. Obesity, 20, 2361-2366.

https://doi.org/10.1038/oby.2012.130

[9] Marrocco, I., Altieri, F. and Peluso, I. (2017) Measurement and Clinical Significance of Biomarkers of Oxidative Stress in Humans. Oxidative Medicine and Cellular Longevity, 2017, Article ID: 6501046. https://doi.org/10.1155/2017/6501046

[10] Catalá, A. (2008) Lipid Peroxidation of Membrane Phospholipids Generates Hydroxy-Alkenals and Oxidized Phospholipids Active in Physiological and/or Pathological Conditions. Chemistry and Physics of Lipids, 157, 1-11. https://doi.org/10.1016/j.chemphyslip.2008.09.004

[11] Del Rio, D., Stewart, A.J. and Pellegrini, N. (2005) A Review of Recent Studies on Malondialdehyde as Toxic Molecule and Biological Marker of Oxidative Stress. $\mathrm{Nu}$ trition, Metabolism \& Cardiovascular Diseases, 15, 316-328. https://doi.org/10.1016/j.numecd.2005.05.003

[12] Levine, R.L., Garland, D., Oliver, C.N., Amici, A., Climent, I., Lenz, A.G., et al. (1990) Determination of Carbonyl Content in Oxidatively Modified Proteins. $\mathrm{Me}$ thods in Enzymology, 186, 464-479. https://doi.org/10.1016/0076-6879(90)86141-H

[13] Dalle-Donne, I., Rossi, R., Giustarini, D., Milzani, A. and Colombo, R. (2003) Protein Carbonyl Groups as Biomarkers of Oxidative Stress. Clinica Chimica Acta, 329, 23-38. https://doi.org/10.1016/S0009-8981(03)00003-2

[14] Yang, S., Jensen, M.K., Rimm, E.B., Willett, W. and Wu, T. (2014) Erythrocyte Superoxide Dismutase, Glutathione Peroxidase, and Catalase Activities and Risk of 
Coronary Heart Disease in Generally Healthy Women: A Prospective Study. American Journal of Epidemiology, 180, 901-908. https://doi.org/10.1093/aje/kwu195

[15] WHO (1995) Physical Status: The Use and Interpretation of Anthropometry. WHO Technical Report Series No. 854, World Health Organization, Geneva.

[16] Dwivedi, A., Singh, S. and Mittal, P.C. (2018) Combining Metal Chelator and Antioxidant Improves Amelioration of Induced Lipid Peroxidation in the Human Erythrocyte Membrane. Journal of Life Sciences, 10, 47-57. https://doi.org/10.31901/24566306.2018/10.01.201

[17] Niehaus, W.G. and Samuelsson, B. (1968) Formation of Malonaldehyde from Phospholipid Arachidonate during Microsomal Lipid Peroxidation. European Journal of Biochemistry, 6, 126-130. https://doi.org/10.1111/j.1432-1033.1968.tb00428.x

[18] Levine, L.R., Garland, D., Oliver, N.C., Amici, A., Climent, I., Lenz, G.A., Ahn, B., Shaltiel, S. and Stadtman, R.E. (1990) Determination of Carbonyl Content in Oxidatively Modified Proteins. Methods in Enzymology, 186, 464-478. https://doi.org/10.1016/0076-6879(90)86141-H

[19] Marklund, S. and Marklund, G. (1974) Involovement of the Superoxide Anion Radical in the Autooxidation of Pyrogallol and a Convenient Assay for Superoxide Dismutase. European Journal of Biochemistry, 47, 469-474. https://doi.org/10.1111/j.1432-1033.1974.tb03714.x

[20] Sinha, A.K. (1972) Colorimetric Assay of Catalase. Analytical Biochemistry, 47, 389-394. https://doi.org/10.1016/0003-2697(72)90132-7

[21] Rotruck, J.T., Pope, A.L., Ganther, H.E., Swanson, A.B., Hafeman, D.G. and Hoekstra, W.G. (1973) Selenium: Biochemical Role as a Component of Glutathione Peroxidase. Science, 179, 588-590. https://doi.org/10.1126/science.179.4073.588

[22] Benzie, I.F. and Strain, J.J. (1996) The Ferric Reducing Ability of Plasma as a Measure of Antioxidant Power: The FRAP Assay. Analytical Biochemistry, 239, 70-76. https://doi.org/10.1006/abio.1996.0292

[23] Sankhla, M., Sharma, T.K., Mathur, K., Rathor, J.S., Butolia, V., Gadhok, A.K., et al. (2012) Relationship of Oxidative Stress with Obesity and Its Role in Obesity Induced Metabolic Syndrome. Clinical Laboratory, 58, 385-392.

[24] Pirinccioglu, G.A., Gökalp, D., Pirinccioglu, M., Kizil, G. and Kizil, M. (2010) Malondialdehyde (MDA) and Protein Carbonyl (PCO) Levels as Biomarkers of Oxidative Stress in Subjects with Familial Hypercholesterolemia. Clinical Biochemistry, 43, 1220-1224. https://doi.org/10.1016/j.clinbiochem.2010.07.022

[25] Rattan, R. and Nayak, D. (2008) High Levels of Plasma Malondialdehyde, Protein Carbonyl, and Fibrinogen Have Prognostic Potential to Predict Poor Outcomes in Patients with Diabetic Foot Wounds: A Preliminary Communication. International Journal of Lower Extremity Wounds, 20, 10. https://doi.org/10.1177/1534734608324124

[26] Paio, A.M., Kang, K.A., Lee, I., Kim, H., Kim, S., Choi, J., et al. (2011) Silver Nanoparticles Induce Oxidative Cell Damage in Human Liver Cells through Inhibition of Reduced Glutathione and Induction of Mitochondria-Involved Apoptosis. Toxicology Letters, 201, 92-100. https://doi.org/10.1016/j.toxlet.2010.12.010

[27] Hopps, E. and Caimi, G. (2013) Protein Oxidation in Metabolic Syndrome. Clinical and Investigative Medicine, 36, E1-E8. https://doi.org/10.25011/cim.v36i1.19399

[28] Ravi Kiran, S.B., Lakshmi, T.M., Srikumar, R. and Reddy, P.E. (2016) Total Antioxidant Status and Oxidative Stress in Diabetes Mellitus and Metabolic Syndrome. International Journal of Pharmaceutical Sciences Review and Research, 40, 271-277. 
[29] Picu, A.A., Stefan, S.P., Mitu, M., Lixandru, D., Tîrgoviste, I.C., Pîrcalabioru, G.G., et al. (2017) Markers of Oxidative Stress and Antioxidant Defense in Romanian Patients with Type 2 Diabetes Mellitus and Obesity. Molecules, 22, 714.

https://doi.org/10.3390/molecules22050714

[30] Bakhtiar, A., Tilak, H.K., Omidvar, S. and Amiri, N.F. (2017) Association of Lipid Peroxidation and Antioxidant Status with Metabolic Syndrome in Iranian Healthy Elderly Women. Biomedical Reports, 7, 331-336.

https://doi.org/10.3892/br.2017.964

[31] Costa, O.J., Cecília, M., Vásquez, P., Santana, G.J., Silva, N.J., Braz, J.M., et al. (2017) Plasma Total Antioxidant Capacity and Cardiometabolic Risk in Non-Obese and Clinically Healthy Young Adults. Arquivos Brasileiros de Cardiologia, 109, 140-147. https://doi.org/10.5935/abc.20170095

[32] Tripathi, R., Gupta, S., Rai, S. and Mittal, P.C. (2011) Effect of Topical Application of Methylsulfonylmethane (MSM), EDTA on Pitting Edema and Oxidative Stress in a Double Blind, Placebo-Controlled Study. Cellular and Molecular Biology, 57, 59-65. 